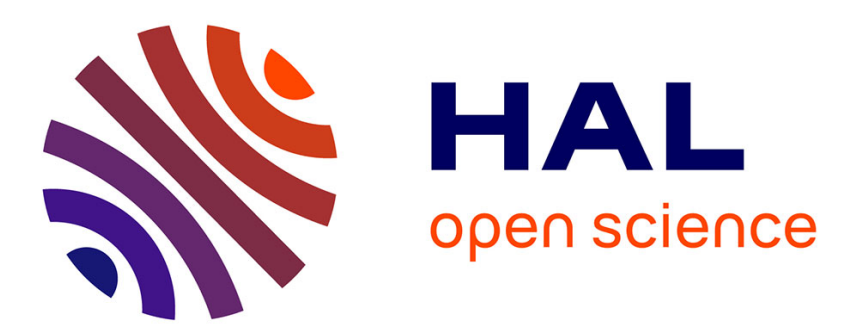

\title{
About the importance of introducing a correction factor in the Sneddon relationship for nanoindentation measurements
}

\author{
Michel Troyon, Sébastien Lafaye
}

\section{- To cite this version:}

Michel Troyon, Sébastien Lafaye. About the importance of introducing a correction factor in the Sneddon relationship for nanoindentation measurements. Philosophical Magazine, 2006, 86 (33-35), pp.5299-5307. 10.1080/14786430600606834 . hal-00513667

\section{HAL Id: hal-00513667 \\ https://hal.science/hal-00513667}

Submitted on 1 Sep 2010

HAL is a multi-disciplinary open access archive for the deposit and dissemination of scientific research documents, whether they are published or not. The documents may come from teaching and research institutions in France or abroad, or from public or private research centers.
L'archive ouverte pluridisciplinaire HAL, est destinée au dépôt et à la diffusion de documents scientifiques de niveau recherche, publiés ou non, émanant des établissements d'enseignement et de recherche français ou étrangers, des laboratoires publics ou privés. 


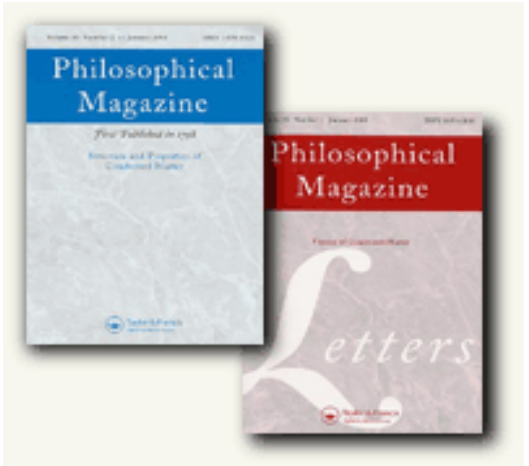

\section{About the importance of introducing a correction factor in the Sneddon relationship for nanoindentation measurements}

\begin{tabular}{|r|l|}
\hline Journal: & Philosophical Magazine \& Philosophical Magazine Letters \\
\hline Manuscript ID: & TPHM-05-Nov-0486.R1 \\
\hline Journal Selection: & Philosophical Magazine \\
\hline Date Submitted by the \\
Author: & 06-Dec-2005 \\
\hline Complete List of Authors: & $\begin{array}{l}\text { Troyon, Michel; University of Reims } \\
\text { Lafaye, Sébastien; University of Reims }\end{array}$ \\
\hline Keywords: & nanoindentation, hardness \\
\hline Keywords (user supplied): & correction factor, Sneddon relationship, contact area \\
\hline &
\end{tabular}

\section{s scholarONE" \\ Manuscript Central}




\begin{abstract}
In the Sneddon relationship between unloading contact stiffness, elastic modulus and contact area, it is absolutely necessary to introduce a correction factor $\alpha$ to perform good elastic modulus and hardness measurements by nanoindentation. This is verified in the present paper by comparing the contact area determined from the Sneddon equation in the usual way, to the projected area of the residual indent measured by AFM. For the fused quartz indented by a sharp Berkovich indenter, the tip radius of which is $180 \mathrm{~nm}$, a $\alpha$ value as high as 1.17-1.19 is evaluated for a load of $10 \mathrm{mN}$ corresponding to a penetration depth of about $300 \mathrm{~nm}$. This correction factor is not a constant having a single value valid for any Berkovich indenter, but strongly depends on the blunting state of the indenter when measurements are performed in the nanoindentation regime, i.e. penetration depths of the order of a few hundreds nanometers.
\end{abstract}

Keywords: nanoindentation; hardness, correction factor; contact area; Sneddon relationship

* Corresponding author. Tel: 333260519 01.E-mail: michel.troyon@univ-reims.fr 


\section{Introduction}

In instrumented indentation, the elastic modulus and hardness are determined from the Sneddon [1] basic fundamental equation

$$
S_{u}=\frac{2}{\sqrt{\pi}} E_{r} \sqrt{A_{c}}
$$

between unloading contact stiffness $S_{u}$, reduced elastic modulus $E_{r}$ and contact area $A_{c}$. Experimentally, the contact area function of the indenter is determined from this above equation by measuring the unloading stiffness of a reference material of known modulus. Then, the indentation hardness is determined by $H=P_{\max } / A_{c}$ and the elastic modulus from Eq. (1) by using the area function determined on the reference material. The basic assumption of the method is that the contact area at maximum load is equal to the projected area of the residual impression, even for an elastic/plastic material [2].

Eq. (1) holds for any punch that can be described by a solid of revolution of a smooth function. In the case of a not axially symmetric indenter, King [3] showed by finite element calculation that a geometrical correction factor $\beta$ should be introduced in Eq. (1) such as:

$$
S_{u}=\beta \frac{2}{\sqrt{\pi}} E_{r} \sqrt{A_{c}} .
$$

For an indenter of triangular cross-section, as for example the Berkovich indenter, the value given by King is $\beta=1.034$. Very recently, Woirgard [4] has analytically demonstrated that the exact value of this geometrical correction factor for the perfectly sharp Berkovich indenter should be $\beta=1.062$.

Several studies suggested that the correction factor could also depend on the material. In the context of a perfect elastic contact Hay et al. [5] show that the correction factor depends on the Poisson's ratio. Studies by Cheng and Cheng [6] and Dao et al. [7], using dimensional analysis and finite element calculations in the case of elastic/plastic materials with work hardening, demonstrate also the existence of this correction factor, suggesting that it also depends on the elastoplastic properties of the material. In a recent review paper, Oliver and Pharr (O\&P) [8] remark that the different studies published on this correction factor give values between 1.023 and 1.085 and they suggest that 1.05 should be probably a good choice with a potential for error of approximately \pm 0.05 . Very recently, Troyon and Huang [9] have experimentally shown that the correction factor strongly depends on the indenter tip radius in the nanoindentation regime, i.e. for penetration depth of about $300 \mathrm{~nm}$ or less. Additionally, these authors have also shown on two other materials, titanium and (100) oriented $\mathrm{MgO}$ monocrystal, that the correction factor is material dependent. From these above results, it seems thus, for resuming, that the correction factor depends on the indenter geometry, but also on the deformation behaviour of the material which is indented.

For a sharp Berkovich indenter of radius $\mathrm{R}=105 \mathrm{~nm}$, Troyon and Huang [9] determined a correction factor of 1.07 , and for the same indenter, which was slightly blunted after several months of utilisation $(\mathrm{R}=350 \mathrm{~nm})$, the correction factor was as high as 1.26 for the fused quartz. These correction factor values were obtained by comparing the contact area deduced from Eq. (1) to the real contact area of a Berkovich indenter modelled by a rigid cone of halfincluded angle of $70.32^{\circ}$ (the angle that gives the same depth-to-area ratio as the berkovich indenter) truncated by a spherical cap. The accuracy of these experimental results depends on how well the fundamental relations used in the analysis of nanoindentation load-displacement 
data allow the determination of elastic modulus and hardness and also on the tip modelling quality. To raise the doubt on the veracity of these measurements, the best way of proceeding, as suggested by one of the referee of their paper, is to precisely measure the projected area of the residual impression on a material, the fused quartz, that is generally considered as a good one since it is used as a reference material. In the present paper, the projected area of the residual impression made in fused quartz is measured by atomic force microscopy and compared on the one hand to the contact area determined from Eq. (1) and on the second hand to two different methods relying both on the equations developed in the O\&P analysis [2]. The first method is based on the tip modelling [9] and the second one on the two-slope method [10-11], which relies on the determination of the slopes of the loading and unloading curves rather than the indenter displacement as an input.

\section{Experimental}

The nanoindentation measurements were carried out with a nanoindenter (Triboscope, Hysitron Inc.) coupled to an atomic force microscope (Nanoscope II, Digital Instruments). Measurements were performed on fused quartz with a Berkovich indenter. The residual impression area was measured with another atomic force microscope (Nanoscope IIIa, Veeco) working in the contact mode, the calibration of which was carefully controlled on a calibrated grating. All the experimental details (compliance determination, load-time sequence, drift correction, etc.) are described in Ref. [9]. Our measurements are based on the O\&P method except that the factor $\varepsilon=0.75$ in the expression of the contact depth $h_{c}=h_{\max }-\varepsilon P_{\max } / S_{u}$ was replaced by the function $\varepsilon(m)$ [12], where $m$ is the exponent of the power-law relation $P=B\left(h-h_{f}\right)^{m}$ which fits the unloading curve, and the area function was obtained by fitting the data according to the function $D\left(h_{c}+\xi\right)^{2}$, where $D$ and $\xi$ are free adjustment parameters, instead of using the polynomial expression proposed by O\&P. The indentation measurements were limited to the range $2-10 \mathrm{mN}$ for which the hardness is depth-independent. The radius of the indenter tip was evaluated by using the Hertzian equation between load and penetration depth $\mathrm{P}=\frac{4}{3} \mathrm{E}_{\mathrm{r}} \sqrt{\mathrm{R}} \mathrm{h}^{3 / 2}$. A mean radius value $\mathrm{R}=180 \pm 19 \mathrm{~nm}$ was calculated from about twenty loading-unloading experiments performed at a very low load $P=20 \mu \mathrm{N}$ so as to stay in the elastic regime.

\section{Description of the methods for measuring the correction factor}

Let us first illustrate, from previous published results [9] that the usual way of measuring the hardness in instrumented nanoindentation leads to a serious issue. When the Sneddon equation (1) is used without correction factor to determine the contact area, the hardness is given by:

$$
H=P_{\max } /\left(\sqrt{\pi} S_{u} / 2 E_{r}\right)^{2} .
$$

Fig. (1) shows two area functions determined for the fused quartz from Eq. (1) plotted versus the contact depth. One curve was obtained with a sharp indenter radius $\mathrm{R}=105 \mathrm{~nm}$ and the other with a blunted indenter of radius $\mathrm{R}=350 \mathrm{~nm}$. The maximum of each curve corresponds to a maximum load $\mathrm{P}=10 \mathrm{mN}$. Therefore, it can be clearly seen that the two indenters do not give the same hardness value, which is very strange since it is the same material. These experimental results suggest that a correction factor for contact area must be introduced in Eq. (1), which should be tip radius dependent. In Eq. (2) the correction factor $\beta$ is strictly related 
to the lack of revolution symmetry of a perfectly sharp indenter. To make the difference between a sharp indenter and a blunted one we will use in the following the notation $\alpha$ for the correction factor, this one taking also into account the material dependence according to the results of Troyon and Huang [9], such as :

$$
S_{u}=\alpha \frac{2}{\sqrt{\pi}} E_{r} \sqrt{A_{c}}
$$

\section{[Insert Fig. 1 about here]}

\section{3-1. Determination of $\alpha$ by tip modelling}

We have modelled the Berkovich indenter by a rigid cone of half-included angle $\varphi$ and a spherical extremity of radius $R$. Then, its area function can be described by

$$
A_{c}=\pi \tan ^{2} \varphi\left(h_{c}+h_{b}\right)^{2}=C\left(h_{c}+h_{b}\right)^{2}
$$

where $\mathrm{C}=24.56$ for the Berkovich indenter and $h_{b}$ is the blunting distance (see Fig. 2) given by

$$
h_{b}=R\left(\frac{1}{\sin \varphi}-1\right) \text {. }
$$

Substituting the value of $A_{c}$ given by Eq. (4) into Eq. (3) allows the determination of $\alpha$ :

$$
\alpha^{2} 24.56\left(h_{c}+h_{b}\right)^{2}=\frac{\pi}{4}\left(\frac{S_{u}}{E_{r}}\right)^{2} .
$$

[Insert Fig. 2 about here]

\section{3-2. Determination of $\alpha$ by the two-slope method}

The principle of the two-slope method, which is an analysis technique rarely used in the literature although very attractive since there is no need to determine the area function, has been first formulated by Oliver [10]. This method relies on the determination of the slopes of the loading and unloading curves, which represent the loading and unloading contact stiffness, respectively, when they are calculated at the maximum penetration depth. Very recently, Troyon and Huang [11] have reformulated the equations in such way that the correction factor $\alpha$ is taken into account and the hardness obtained with the two-slope method is in agreement with that given by the usual O\&P method determined by Eq. (3). The main equations are recalled below.

The load-depth relationship is :

$$
P=E_{r}\left(\frac{1}{\sqrt{C \alpha^{2}}} \sqrt{\frac{E_{r}}{H}}+\varepsilon \frac{\sqrt{\pi}}{2} \sqrt{\frac{H}{E_{r}}}\right)^{-2}\left(h+h_{b}\right)^{2}
$$

The reduced modulus and the hardness are given by

$$
\begin{aligned}
& E_{r}=\sqrt{\frac{\pi}{C}} \frac{1}{2 P \alpha}\left(\frac{S_{u}^{2} S_{l}}{2 S_{u}-\varepsilon S_{l}}\right), \\
& H=\frac{1}{C \alpha^{2}} \frac{1}{P}\left(\frac{S_{u} S_{l}}{2 S_{u}-\varepsilon S_{l}}\right)^{2},
\end{aligned}
$$

where $S_{l}$ is the loading slope, and the contact area is : 


$$
A_{c}=C P^{2}\left(\frac{2 S_{u}-\varepsilon S_{l}}{S_{u} S_{l}}\right)^{2} .
$$

From Eq. (9), knowing the reduced modulus of the material and measuring $S_{u}$ and $S_{l}$ at $P_{\max }$, the correction factor $\alpha$ can be easily determined. The way we have measured the loading and unloading slope is explained in Ref. [11].

\section{3-3. Measurement of the projected area by AFM}

Fig. 3 shows the AFM images of the residual impression. In Fig. 3a the area is measured by considering that the area corresponds to the area of the triangle joining the edges of the imprint and in Fig. 3b we have used a flooding method (WSxM v4.0 software from Nanotec company) which delimits all the points of the image having the same height (or depth) with respect to a reference height (or depth). In the present case, the algorithm fills up the inside of the indentation till the surface, i.e., determines all the pixels having a height equal to the residual penetration depth, the bottom of the indent serving as the height reference.

\section{[Insert Fig. 3 about here]}

\section{Results and discussion}

In table 1 are reported the values of the contact areas measured by the different methods for indentations made at $P=10 \mathrm{mN}$ with a Berkovich indenter with a radius $R=180 \pm 19 \mathrm{~nm}$. The corresponding $\alpha$ and hardness values are also given. For the usual method, $\alpha=1$, the contact area is $A_{c}=(\pi / 4)\left(S_{u} / E_{r}\right)^{2}$, and the hardness is given by Eq. (3). For the tip modelling method $A_{c}=24.56\left(h_{c}+h_{b}\right)^{2}$ and $\alpha$ is determined from Eq. (7). The accuracy with which $\alpha$ is determined is evidently related to the measurement accuracy of each parameter intervening in Eq. (7), that are $S_{u}, h_{c}$ and $h_{b}$. The blunting distance $h_{b}$ plays a particular role. Its determination depends on the quality of the tip modelling, and its contribution to the error on $\alpha$ depends on the magnitude of $h_{c}$. In the present experiment $h_{c} \sim 160 \mathrm{~nm}$ and $h_{b} \sim 11 \mathrm{~nm}$. Therefore, $10 \%$ error on $h_{b}$ leads to an error on $\alpha$ of about $0.6 \%$. The determination of $S_{u}$ and $h_{c}$ results from the analysis of the unloading curve, that is mainly from the elastic properties of the material. One may thus think here that $\alpha$ not only depends on the indenter geometry but is also sensitive to the elastic properties of the material. It has been shown by finite element calculations [13] that the O\&P method fails to determine the contact depth well in case of pile-up and thus, in that case, the correction of the Sneddon relationship is partly inefficient. Only a measure of the amount of pile-up, for example by AFM profiling, could allow a correct determination of the hardness.

For the two-slope method $\mathrm{A}_{\mathrm{c}}$ is given by Eq. (11) and $\alpha$ is determined from Eq. (9). The accuracy on $\alpha$ is directly related to the measurement accuracy with which the loading and unloading slopes are determined. One will remark that the two-slope method is based on the same set of equations and assumptions used in the O\&P analysis and thus the two-slope method suffers from the same drawbacks as the O\&P method. Contrary to the tip modelling method, $\alpha$ does not depend on the contact depth, but is sensitive to the loading curve, therefore to the plastic deformation. One may thus think here that $\alpha$ will not only correct for the indenter geometry defects but will take better into account the material deformation behaviour. 
For the AFM measurements the area is directly obtained from the images and the corresponding values of $\alpha$ are obtained by writing $(\pi / 4)\left(S_{u} / E_{r}\right)^{2}=\alpha^{2}\left(A_{c}\right)_{A F M}$. Fig. $3 \mathrm{~b}$ clearly shows that the sides of the imprint present a curvature towards its centre. This can be caused either by differential elastic recovery after unloading or by some degree of surface sink-in due to material movement during loading. Therefore, taking the area of the indentation as a perfect triangle leads to measurement errors. Nevertheless, to measure the area in this way presents some interest for the comparison with the tip modelling and the two-slope methods, because the triangle corresponds better to the shape of the indenter when it is pressed against the material at maximum load.

All the measurements that are given in Table 1 are the mean values of six different indentations. The errors of measurements on the contact areas and hardness values are evaluated to be of the order of $\pm 5 \%$.

\section{[Insert Table 1 about here]}

It can be noticed that the indent area measured by the flooding method is the smaller one. That is the closest to the reality which correspond to the Meyer hardness definition. The contact area obtained by the usual method is largely overestimated and leads to a hardness underestimated by $30 \%$ with respect to that obtained from AFM measurement by the flooding method. The area measured by AFM from the indent considered as a triangle is in good agreement with the area measured by the two-slope method. Indeed, as explained above the shape of the contact area at maximum load is inevitably a triangle. It seems that the area measured from the tip modelling is in less good agreement than that obtained by the two-slope method. This may seem normal since the model does not fit exactly with the real shape of the indenter. The extremity of the Berkovich indenter cannot be considered exactly as a spherical tip and the radius that we have measured by the herztian theory is just an equivalent radius.

Troyon and Huang [9] have measured $\alpha=1.07$ and 1.26 for a tip radius $\mathrm{R}=105$ and $350 \mathrm{~nm}$, respectively, by using the tip modelling method, and $\alpha=1.31$ for $\mathrm{R}=350 \mathrm{~nm}$ by the two-slope method [11]. Herein, for an intermediate radius $\mathrm{R}=180 \mathrm{~nm}$, the values of $\alpha$ are 1.12 by tip modelling and 1.15 by the two-slope method. These results confirm thus the extreme sensitivity of the correction factor to the blunting state of the indenter and show that it is especially important not to forget the existence of the correction factor in the Sneddon equation (1) when indentation are performed in the nanoindentation regime, i.e. when the penetration depth is in the range of a few hundreds of nanometers. The comparison with AFM measurements raises the doubt, if any, concerning so important $\alpha$ values.

Evidently, more the penetration depth is important (microindentation regime) and less the magnitude of $\alpha$ is. Indeed, a slightly blunt indenter has less influence at penetration depth of several micrometers and can be considered as a sharp one. Nevertheless, according to the analytical calculations of Woirgard [4], the minimum value that the correction factor could take should be 1.062 for a Berkovich indenter, which is already a non negligible correction that merits to be taken into account and not forgotten as it is often the case in a large majority of papers published in the literature.

\section{Conclusion}


The usual way of determining the contact area in instrumented indentation from the Sneddon equation is compared to the projected area of the residual indent measured by AFM, to the contact area determined from the two-slope method and also to the contact area of a Berkovich indenter modelled by a cone truncated by a spherical cap. The measurements are performed on the fused quartz, at a load of $10 \mathrm{mN}$, with a pretty sharp indenter the radius of which is $180 \mathrm{~nm}$. The contact area determined from the Sneddon equation is strongly overestimated with respect to that measured by AFM, of the order of 35 to $40 \%$, indicating that a correction factor must be absolutely introduced in the Sneddon equation. This correction factor, in the present experiment, is 1.19 or 1.17 for the AFM measurements, 1.15 with the two-slope method, and 1.12 with the tip modelling. Therefore, it is extremely important to determine this correction factor for each specific indenter used during an indentation test, chiefly in the nanoindentation regime, i.e. for depths of the order of a few hundreds of nanometers. The two-slope method seems to be a good and easy method to correctly evaluate the correction factor. Finally, we would like to conclude by drawing the attention of the nanoindentation community on the fact that the correction factor is not a universal constant having a single value which would be defined by the type of indenter, since its value depends on the blunting state of the indenter and also on the material tested as shown by one of the present authors in a previous paper. 


\section{Achnowledgements}

The financial support of the French government and the Champagne Ardenne Region Council in the framework of the Pôle Mécanique Matériaux Champardenais (PMMC) are gratefully acknowledged. 


\section{References}

[1] I.N. Sneddon, Int. J. Eng. Sci 347 (1965).

[2] W.C. Oliver and G.M. Pharr, J. Mater. Res. 7564 (1992).

[3] R.B. King, Int. J. Solids Structures 231657 (1987).

[4] J. Woirgard, oral communication presented at the Instrumented Indentation Testing in Materials Research and Development conference, Heraklion, Crete, Greece, 10-14 October (2005).

[5] J.C. Hay, A. bolshakov and G.M. Pharr, J. Mater. Res, 142296 (1999).

[6] Y-T. Cheng and C-M. Cheng, J. Appl. Phys. 841284 (1998).

[7] M. Dao, N. Chollacoop, K.J. Van Vliet, T.A. Venkatesh and S. Suresh, Acta. Mater. 49 3899 (2001).

[8] W.C. Oliver and G.M. Pharr, J. Mater. Res. 193 (2004).

[9] M. Troyon and L. Huang, J. Mater. Res. 20610 (2005).

[10] W.C. Oliver, J. Mater. Res. 163202 (2001).

[11] M. Troyon and L. Huang, J. Mater. Res. 202194 (2005).

[12] M. Martin and M. Troyon, J. Mater. Res. 172227 (2002).

[13] A. Bolshakov and G.M. Pharr, J. Mater. Res. 131049 (1998). 


\section{Figure captions}

Fig. 1 : Calculated contact area versus contact depth for the fused quartz and a sharp $(\mathrm{R}=105$ $\mathrm{nm})$ and blunt $(\mathrm{R}=350 \mathrm{~nm})$ Berkovich indenter tips, fitted with the function $C\left(h_{c}+\xi\right)^{2}$. The maximum of each curve corresponds to a load of $10 \mathrm{mN}$.

Fig. 2 : Indenter modelled by a rigid cone of half-included angle $\varphi$ and a spherical extremity of radius $R$.

Fig. 3 : AFM images $1.9 \times 2 \mu \mathrm{m}^{2}$ of the residual impression made in fused quartz at $\mathrm{P}=10 \mathrm{mN}$ with a Berkovich indenter the radius of which is $\mathrm{R}=180 \mathrm{~nm}$. In image 3(a), the projected area equals the triangle area and in image 3(b) a flooding method is used to delimit the area corresponding to the points of the image having the same depth as that of the residual depth.

Table 1 : Values of the contact areas measured by the different methods and the corresponding correction factor and hardness values. 


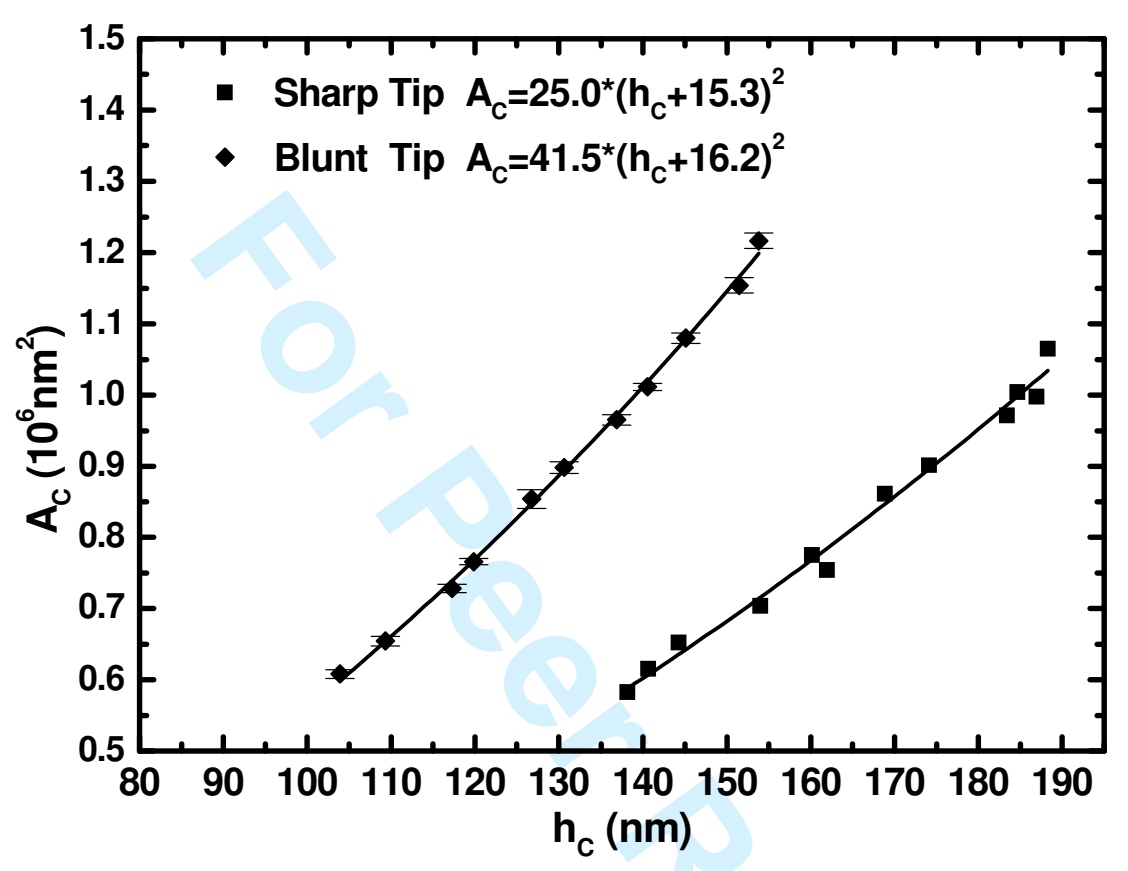

Fig 1 


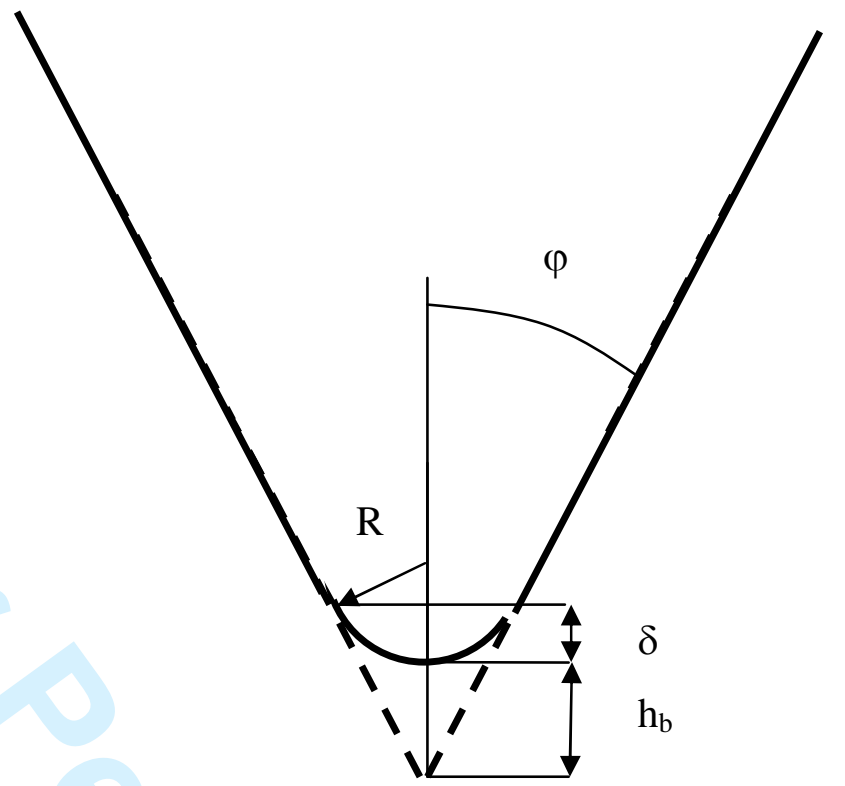

Fig 2 
(a)

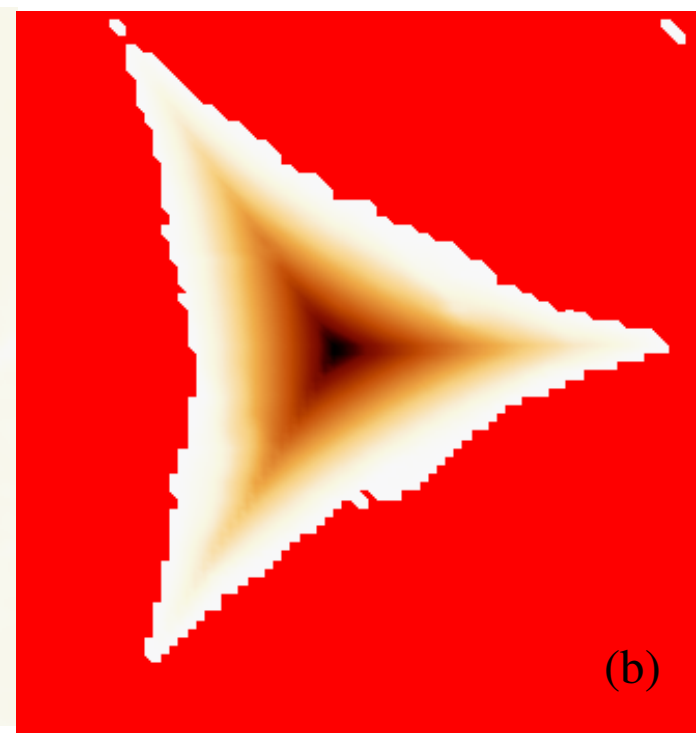

Fig. 3 
Table 1

\begin{tabular}{|c|c|c|c|c|c|}
\hline & $\begin{array}{c}\text { Usual } \\
\text { method }\end{array}$ & $\begin{array}{c}\text { Tip } \\
\text { modelling }\end{array}$ & $\begin{array}{c}\text { 2-slope } \\
\text { method }\end{array}$ & $\begin{array}{c}\text { AFM } \\
\text { triangle }\end{array}$ & $\begin{array}{c}\text { AFM } \\
\text { flooding }\end{array}$ \\
\hline $\mathrm{A}_{\mathrm{c}}\left(\mu \mathrm{m}^{2}\right)$ & 1.2 & 0.95 & 0.92 & 0.89 & 0.85 \\
\hline$\alpha$ & 1 & 1.12 & 1.15 & 1.17 & 1.19 \\
\hline $\mathrm{H}(\mathrm{GPa})$ & 8.3 & 10.5 & 10.8 & 11.2 & 11.7 \\
\hline
\end{tabular}

